\title{
EDUCAÇÃO EM SAÚDE NA ESCOLA: VIVÊNCIA INTERDISCIPLINAR NA FORMAÇÃO DOCENTE EM UM PROJETO DE EXTENSÃO UNIVERSITÁRIA
}

\author{
Luís Felipe Pissaia ${ }^{1}$, Marli Teresinha Quartieri² ${ }^{2}$, Rogério José Schuck ${ }^{3}$, \\ Suzana Feldens Schwertner ${ }^{4}$
}

Resumo: Trata-se de um relato de experiência docente no projeto de extensão universitária Veredas da Linguagem, vinculado ao curso de Letras da Universidade do Vale do Taquari - UNIVATES, que atua frente ao ensino de língua portuguesa e estratégias de leitura a imigrantes haitianos residentes no Vale do Taquari/RS por meio do desenvolvimento de objetos digitais de aprendizagem. Compreendeu-se que o projeto possui um viés comunitário com responsabilidade social e atua como apoiador da rede municipal de ensino. Vivenciou-se a atuação interdisciplinar como característica marcante do projeto, instruída através da comunicação e troca de experiências entre distintos profissionais. Considera-se que o perfil do enfermeiro enquanto educador é amplo e necessário na sociedade atual, instrumentalizado pelos diferentes saberes e competências desenvolvidas. O "desacomodar" tornou-se palavra chave no processo de construção do ser professor que se alavancou como um desafio motivador perante a situação. Neste sentido, considera-se que a formação do professor sob a realidade interdisciplinar propicia a construção de um processo de ensino e aprendizagem pautado no saber refletivo e interativo com a atualidade.

Palavras-chave: Formação docente; Educação em Saúde; Extensão Universitária; Interdisciplinaridade; Enfermagem.

1 Graduado em Enfermagem. Mestrando em Ensino pela Universidade do Vale do Taquari UNIVATES. E-mail: 1pissaia@universo.univates.br

2 Graduada em Ciências e Matemática. Mestra em Matemática Aplicada. Doutora em Educação. Professora do PPGEnsino da Universidade do Vale do Taquari - UNIVATES. E-mail: mtquartieri@ univates.br

3 Graduado em Filosofia pela Faculdade de Filosofia Nossa Senhora da Imaculada Conceição. Pósgraduado em Gestão Universitária pela Univates. Mestre e Doutor em Filosofia pela PUCRS. Professor do PPGEnsino da Universidade do Vale do Taquari - UNIVATES. E-mail: rogerios@univates.br

4 Graduada em Psicologia pela UFRGS. Mestra e Doutora em Educação pela UFRGS. Professora do PPGEnsino da Universidade do Vale do Taquari - UNIVATES. E-mail: suzifs@univates.br 


\title{
HEALTH EDUCATION IN SCHOOL: INTERDISCIPLINARY LIVING IN TEACHING TRAINING IN A UNIVERSITY EXTENSION PROJECT
}

\begin{abstract}
This is an account of teaching experience in the project of university extension Veredas da Linguagem, linked to the course of Letters of the University Center UNIVATES, that works in front of the teaching of Portuguese language and strategies of reading to Haitian immigrants residing in the Vale do Taquari / RS through the development of digital learning objects. It was understood that the project has a community bias with social responsibility and acts as a supporter of the municipal education network. The interdisciplinary work was experienced as a characteristic feature of the project, instructed through communication and exchange of experiences among different professionals. It is considered that the profile of nurses as educators is broad and necessary in today's society, instrumented by the different knowledge and skills developed. "Disappointing" has become a key word in the process of building a teacher who has leveraged himself as a motivating challenge to the situation. In this sense, it is considered that the teacher's formation under the interdisciplinary reality propitiates the construction of a process of teaching and learning based on reflective and interactive knowledge with the present time.
\end{abstract}

Keywords: Teacher training; Health education; University Extension; Interdisciplinarity; Nursing.

\section{INTRODUÇÃO}

A escola contemporânea instrumentaliza-se por meio da atuação de um professor que desenvolve o ensino de modo prazeroso e dinâmico na formação de competências de seus alunos, que conforme Gauthier (2006) compõe-se de um indivíduo com saberes específicos devido ao domínio de sua própria formação interdisciplinar. Nesse sentido, o perfil do educador compreende a diversidade de aspectos que o torna capaz de modificar o meio, ou, conforme Ghedin (2009), um sujeito reflexivo que desempenha uma prática constante de reflexão sobre o fazer e o saber fazer, construindo sua própria experiência.

Fundamentalmente, a prática pedagógica é o principal componente da formação do professor, segundo Masetto (2008), considerando as especificidades que o campo da aprendizagem representa a partir das experiências anteriores do aluno e do próprio professor. A formação de professores do século XXI é vislumbrada por Anastasiou e Pimenta (2002) como a possibilidade de construção de um novo perfil, construído a partir de vivências científicas e tecnológicas e pautado no desenvolvimento de um conhecimento coletivo baseado na atuação interdisciplinar.

Para tanto, tendo-se como base o perfil, pressupõe-se que seu papel na escola contemporânea transpõe as barreiras físicas e normativas, Nóvoa (2009) traz à tona a inserção do professor no contexto comunitário, como influenciador na desconstrução de paradigmas e detentor de um compromisso social e político a partir de sua dualidade pessoa-professor. A formação de professores torna-se algo desafiador, inquietante e do mesmo modo subjetivo por abarcar a conjuntura do próprio indivíduo, neste sentido, 
Demo (2004, p. 10) em analogia à reprodução e construção do conhecimento diferencia a "máquina-professor" do ser humano ou professor ideal, enfatizando:

As máquinas não são autopoiéticas, reproduzem informação, porque são equipamentos lineares, algorítmicos, sequenciais. O ser vivo, em particular, o ser humano é eminentemente semântico, capta e produz significado, entende por linhas tortas, vislumbra lógica na falta de lógica e falta de lógica na lógica, interpreta ausências e silêncios como mensagens, perscruta na greta das palavras e falas, percebe o dito no não dito, depreende a revelia do ato falho.

A formação de um educador atual compreende outro aspecto, que transversalmente é contextualizado por Libâneo (2001) como a formação interdisciplinar, levando-se em consideração a construção individual aliada à interação com os demais profissionais a fim de qualificar a prática pedagógica. Sob este limiar, a formação do professor, pautada em práticas interdisciplinares torna-se um dos desafios da escola contemporânea, sendo o tema deste relato de experiência apresentado.

A presente reflexão parte de uma experiência docente realizada durante o segundo semestre de 2016 no eixo Linguagem e Tecnologia, um dos vários eixos que compõem o projeto de extensão Veredas da Linguagem, vinculado ao curso de Letras da Universidade do Vale do Taquari - UNIVATES. Um dos objetivos deste projeto é desenvolver objetos digitais de aprendizagem que auxiliem no ensino de língua portuguesa e estratégias de leitura aos imigrantes, principalmente haitianos, que residem no Vale do Taquari/RS.

\section{RESULTADOS E DISCUSSÃO}

Este relato de experiência versa sobre a formação interdisciplinar do professor, embasando-se sob aspectos fundamentais que são levantados a partir de bibliografias contemporâneas. Inicialmente busca-se apresentar ao leitor um pouco da construção do projeto, bem como seu compromisso com a comunidade, por meio da categoria denominada, "A transversalidade que compõe o contexto". Após realizou-se uma reflexão quanto a formação em enfermagem e sua inter-relação com a docência, na categoria nomeada de "A Formação do enfermeiro enquanto educador", e na última categoria, "A construção do ser professor", dissertou-se sobre os aspectos presentes na formação docente e sua importância para a qualificação do conhecimento. Os relatos do docente atrelados aos aportes teóricos da área buscam realizar uma reflexão acerca da temática central do texto, compartilhando com o público uma vivência interdisciplinar da escola contemporânea. 


\section{A transversalidade que compõe o contexto}

O contexto da imigração haitiana no Vale do Taquari compreende uma consonância de eventos que envolveram aspectos históricos, sociais, culturais e ambientais, com impacto fundamental após o terremoto ocorrido em 2010 no Haiti (AUDEBERT, 2012). Após o desastre ambiental, a população desolada começou a procurar o Brasil e outros países como destino, tendo como ponto de referência cidades do estado do Acre, de onde empresas do sul do país recrutaram estes imigrantes com o intuito de suprir as necessidades de mão de obra primária escassa na região (MEJÍA; CAZAROTTO; GRANADA, 2015).

Os imigrantes que se estabeleceram na região provêm de diversas regiões do Haiti, possuindo dentre suas características o domínio do dialeto Kréole, uma minoria que possuía acesso à educação em seu país fala fluentemente espanhol, francês e inglês (CAVALCANTI; OLIVEIRA; TONHATI, 2015). Neste sentido, a comunicação verbal tornou-se um limitante nas relações sociais e principalmente no acesso a serviços básicos que necessitavam, tais como a saúde e emprego (MORAES; ANDRADE; MATTOS, 2013).

A partir da necessidade deste grupo populacional, o projeto de extensão Veredas da Linguagem inseriu-se no contexto educacional como apoiador da rede municipal de ensino, sendo que os propósitos do eixo trabalhado foram o desenvolvimento de objetos digitais de aprendizagem durante o ano de 2016; a escolha e composição dos objetos seguiu a perspectiva teórica dos gêneros do discurso. $\mathrm{Na}$ área da linguística, os gêneros de discurso assumem formatos padrões ou "estáveis" conforme definido por Bakhtin (2003), possuindo como determinantes frequentes os valores individuais, sociais e culturais, os quais permeiam os sujeitos mesmo em estado de desconhecimento.

Com base nos determinantes, os participantes desenvolveram atividades com intuito de gravar vídeos e utiliza-los como objetos de aprendizagem: o teor das gravações compreendia ações cotidianas envolvendo família, saúde, emprego, dentre outras. Após a definição e desenvolvimento dos objetos, os mesmos foram apresentados para as turmas e utilizados como base para outras atividades relacionadas ao ensino e leitura da língua portuguesa. A utilização de objetos digitais de aprendizagem discutida por Zancanaro e Amiel (2017) verificou a utilização destes recursos como inovadores e sustentáveis para a escola contemporânea, compondo o casting de modelos educativos mais utilizados atualmente.

Nesta etapa, o docente foi convidado pelos coordenadores do projeto a ministrar uma aula a duas turmas dos turnos da manhã e tarde. $\mathrm{O}$ tema solicitado, consonante com o conteúdo dos vídeos, englobava noções básicas de acesso à rede de serviços de saúde, qualidade de vida, Doenças Crônicas Não Transmissíveis (DCNT), educação sexual e métodos contraceptivos. O docente recebeu o convite devido a já ter ministrado aulas em outros projetos envolvendo o contexto "saúde e imigração", além de participar efetivamente em projetos de educação continuada de funcionários da instituição de ensino e ser pesquisador voluntário em projetos de pesquisa da área. 


\section{Formação do enfermeiro enquanto educador}

O ensinar trata-se de um processo contínuo de aperfeiçoamento, desconstrução e construção do conhecimento. Na área da Enfermagem, a formação enquanto educador vem sendo discutida e reformulada principalmente após a década de 80, impulsionada pela implementação da Lei do Exercício Profissional, que regulamenta as ações da equipe de Enfermagem (BRASIL, 1986). Em um patamar histórico, a profissão foi claramente influenciada pela Conferência Internacional de Educação, que aconteceu em março de 1990 na cidade de Jomtien, na Tailândia, espaço este que deu abertura à construção da Declaração Mundial sobre Educação para Todos, que mais tarde resultaria no Relatório Delors (DELORS et al., 1999).

Em sua obra, Delors et al. (1999) apresentam a discussão do eixo estrutural da educação a partir de quatro modos de aprendizagem, que necessariamente devem ocorrer durante toda a vida do indivíduo, sendo elas: aprender a conhecer; aprender a fazer; aprender a viver juntos e aprender a ser. As quatro aprendizagens elencadas são tratadas como pilares da educação brasileira moderna, além de outros países e chegaram a ser definidas por Antunes (2001) como um guia para a atuação do professor na educação atual.

Sob esta perspectiva, o enfermeiro enquanto educador recebeu a contribuição direta destes documentos, e sempre esteve presente na trajetória do docente no que diz respeito à formação de competências diferenciadas no ensino da enfermagem. Com a vivência recente de graduando em enfermagem, torna-se claramente perceptível os desafios que compõem a formação de competências do professor por meio do contexto social e político que se desenha em nosso país na área da saúde, ao passo que tornamonos responsável pela formação de nossos próprios colegas.

Para Faustino e Egry (2002), a introdução de competências no ensino superior, principalmente na área da enfermagem, vem ganhando destaque internacionalmente por ocasionar mudanças profundas nos currículos escolares; tal linha é trabalhada fortemente no Canadá, França e Bélgica. Colaborando com a afirmativa, Libâneo (2002, p.7) reforça o poder de mudança que o professor desempenha, enfatizando: “(...) não há reforma educacional, não há proposta pedagógica sem professores, já que são os profissionais mais diretamente envolvidos com os processos e resultados da aprendizagem".

A experiência enquanto docente trouxe à tona vários questionamentos que abarcavam toda a formação do enfermeiro através de competências visando ser educador, e a partir desta reflexão pode ser destacado a importância da educação continuada, principalmente em tempos atuais, onde as práticas estão em constante aperfeiçoamento. Compreendendo ainda os benefícios que a formação a partir de competências proporciona na docência como um referencial crítico e reflexivo, sendo influenciado pelas vivências interativas principalmente interdisciplinares que incitam o compromisso social por meio da educação. 
A importância de competências profissionais é introduzida por Tardif e Lessard (2011) como experiências práticas que instrumentalizam a construção do indivíduo enquanto educador, sendo que a interação social ou aluno-professor ganha forma no espaço de legitimação de seu conhecimento específico. No entanto a formação de competências não se restringe ao acúmulo de conhecimento, Perrenoud (2000) delimita que estas construções são apoiadas pela subjetividade da resolução de técnicas, formação política e ética do indivíduo.

Para tanto, a atuação docente do enfermeiro por meio das competências até aqui discutidas é entendida por Mello e Ribeiro (2002) como a experiência adquirida pela prática constante. Sob este aspecto, Gadotti (2000) defende o papel e compromisso da escola na formação ou transformação deste futuro profissional em educador, considerando seus aspectos individuais e utilizando-os como base para a reflexão e problematização.

\section{A construção do ser professor}

O ser professor não é algo fácil. No decorrer da trajetória acadêmica, o envolvimento com atividades de docência com diversos públicos, desde aulas tradicionais e expositivas até práticas em laboratório e uso de objetos tecnológicos como apoio fortalecem o desenvolvimento da competência docente. Nesta experiência relatada, em especial, a proposta desacomoda, não pelo conteúdo abordado, mas pelo perfil dos alunos em questão.

Neste sentido, o "sentir" desacomodado frente a algo novo leva à uma reflexão sobre a possibilidade de trabalhar com outros objetos, diferentes dos usuais, e a este exercício de reflexão sobre aquilo que fazemos e como fazemos, podemos dar o nome de "técnica". Heidegger (2007, p. 380), ao discutir sobre técnica e como trabalhamos com ela no cotidiano, nos leva a refletir ou como o autor cita "desabrigar" a mesma, ao passo que após desabrigar ou desvelar algo, novas possibilidades surgem e se mostram, conforme enfatizado no trecho:

A técnica não é, portanto, meramente um meio. É um modo de desabrigar. Se atentarmos para isso, abrir-se-á para nós um âmbito totalmente diferente para a essência da técnica. Trata-se do âmbito do desabrigamento, isto é, da verdade. [...] Ela desabriga o que não se produz sozinho e ainda não está à frente e que, por isso, pode aparecer e ser notado, ora dessa, ora daquela maneira.

E o "desacomodar" deste desafio contribuiu para experimentar uma nova realidade nunca antes apresentada na atuação docente. Compara-se esta vivência com a reflexão sobre as compreensões de um jogo feitas por Schuck e Neuenfeldt (2009), presumindo que a atuação docente seria a participação em um jogo, sua subjetividade torna o jogador fascinado e motivado a realizar as tarefas levando em consideração suas próprias 
concepções das situações levantadas, e abrindo-se ao trabalho em conjunto, fato este que todos os jogadores terão suas próprias concepções sobre o meio.

Buscando instrumentalizar a participação docente na atividade proposta, realizase uma breve apresentação dos conteúdos solicitados ao grupo de professores, bolsistas e voluntários do projeto. A discussão instruiu diferentes concepções sobre a abordagem inicial do docente, que contribuíram no sentido de compor uma estratégia de ensino baseada na avaliação do perfil situacional dos alunos.

Para a implementação de uma estratégia de ensino incorporou-se o contexto perante o nível de compreensão, escrita e leitura da língua portuguesa, bem como os aspectos culturais, sociais, econômicos e demográficos de se desenhavam sobre aquele grupo. Foram levados em consideração aspectos físicos da sala de aula (tamanho, luminosidade) e disponibilidade de ferramentas de apoio (computador, projetor multimídia, quadro negro, etc.). Considerou-se este contexto, pois o mesmo possui importância na construção do conhecimento, por delimitar a forma como o ensino será realizado em sala de aula e como os estudantes se colocarão frente a tal.

A composição do conteúdo abordado foi de noções básicas de acesso à rede de serviços de saúde, qualidade de vida, Doenças Crônicas Não Transmissíveis (DCNT), educação sexual e métodos contraceptivos. Após várias reflexões sobre todos os aspectos levantados, considerou-se a estratégia de realização de aula expositiva-dialogada com o apoio de recursos do PowerPoint, materiais didáticos para compreensão (camisinhas masculinas e femininas, dispositivo intrauterino-DIU, dentre outros) e moldes em silicone de órgãos genitais humanos.

Quanto aos aspectos tecnológicos na escola contemporânea torna-se imprescindível a utilização de recursos disponíveis em cada realidade. As tecnologias tornaram-se uma ferramenta de auxílio nas aulas, por desempenhar um papel de apoio ao docente, de modo que, como exemplo, o computador possibilitou a realização de buscas na internet simultaneamente às explicações. Schuck et al. (2013), em uma pesquisa realizada com mestrandos das regiões Norte, Nordeste e Sul, concluíram que as ferramentas tecnológicas, principalmente as Tecnologias da Informação e Comunicação (TIC), fazem parte dos processos de ensino e aprendizagem da atualidade, sendo que cabe ao professor utilizá-las de maneira que sirvam como apoio para sua prática.

Os conteúdos foram abordados e discutidos pelo docente e alunos a partir da utilização de imagens com conteúdo técnico, demonstrando situações e casos onde determinada conduta seria empregada. Pode-se ter como exemplo imagens de diferentes instituições de saúde dentro de uma composição urbana, para explicar o funcionamento da rede de apoio a saúde municipal. A reflexão a partir de fotos ou imagens é evocada por Schwertner e Conrad (2016) em uma pesquisa realizada com estudantes de Ensino Fundamental e Médio, onde os mesmos produziram as imagens e constatou-se que o sentido visual resgata emoções ao observador, que traz para discussão comentários que contextualizam o objeto trabalhado com as suas próprias vivências. 
A sala de aula foi organizada de modo que os alunos ficassem acomodados em um semicírculo, com a projeção multimídia e o quadro negro a sua frente. Sendo que o docente colocou-se frente aos alunos circulando pelo espaço, lançando primeiramente uma reflexão sobre qualidade de vida. Sendo que os alunos trouxeram suas próprias experiências e significados sobre o tema. As técnicas de flexibilização dos espaços em sala de aula, como a disposição dos alunos e posicionamento do professor possibilitam um contato maior com o aluno, aproximando ambos da discussão, a libertação de modelos escolares estereotipados, que colocam o professor como centro do saber e distante do aluno são tratados em uma reflexão do filme "Entre os Muros da Escola", de Pastoriza e Pino (2015), que perpassam a conjuntura dos espaços escolares em detrimentos aos sujeitos que habitam tais espaços. Neste sentido, com o método utilizado colocou-se o aluno como responsável pela própria construção do conhecimento, fazendo-o refletir sobre os assuntos.

Durante a realização das aulas, o docente contou com o apoio de outros docentes e bolsistas do próprio projeto Veredas da Linguagem. Concomitante as explicações que seguiram durante a aula os demais apoiadores resgatavam questões de aprendizagem básicas, como a leitura e escrita, demonstrando a eficácia da interdisciplinaridade na construção do conhecimento em diferentes espaços. A participação de diferentes profissionais atuando juntos no mesmo espaço da sala de aula sintetiza a integração interdisciplinar que Carvalho (1998, p. 9) designa como "[...] superar uma visão especializada e fragmentada do conhecimento em direção à compreensão da complexidade e da interdependência dos fenômenos da natureza e da vida". Trazendo à discussão a necessidade de produção interdisciplinar do conhecimento na escola contemporânea como meio de atingir os alunos em suas diferentes realidades. Podendose discorrer sobre os cenários em que o ensino se faz presente, além dos diferentes níveis de dificuldades dos alunos, neste caso as dificuldades na fala, leitura e escrita foram evidenciadas durante as aulas, o que de certo modo impacta no modo como o professor ministra sua aula, sendo necessário muito mais do que técnica, mas compromisso e dedicação em ensinar.

As aulas contaram com momentos avaliativos de abordagem reflexiva, de modo que os próprios alunos trouxeram o seu ponto de vista sobre a importância da abordagem do conteúdo pelo projeto, colaborando com a contextualização interdisciplinar proposta. Em suas falas destacaram que não sabiam de determinadas informações, como por exemplo, o funcionamento da rede municipal de saúde, ou da transmissão de determinadas DSTs. A relação de aprendizagem através da reflexão crítica e resolução de problemas de cunho interdisciplinar sobre o meio é trazida por Freire (1996) como uma estratégia de construção de conhecimento a partir da bagagem cientifica e empírica do próprio aluno, levando-se em consideração ambas e tratando-as como meios para o ensino e aprendizagem. A bagagem cultural trazida pelos imigrantes permeia todo o processo de construção do conhecimento, pois os mesmos contextualizavam as experiências individuais com as informações repassadas sobre a realidade local, sendo possível compreender seu funcionamento. 


\section{CONSIDERAÇÕES FINAIS}

Ser docente é uma experiência extraordinária: interagir, refletir, conhecer, compartilhar e construir conhecimento em conjunto torna-se transformador tanto para o profissional, quanto para o aluno. Com base neste relato compreendeu-se que a escola é um espaço de interação e integração da diversidade do saber reflexivo, que é construído a partir da contextualização que o aluno e o professor fazem de seu próprio meio.

A experiência aprofundou e dialogou sobre diferentes aspectos da formação do professor e o papel da escola na contemporaneidade, inserindo-os em um ambiente interdisciplinar, o que estimula a problematização de diferentes realidades a partir de estratégias de ensino e aprendizagem. A participação no projeto de extensão Veredas da Linguagem possibilitou vivenciar a atuação interdisciplinar proposta nos diferentes cenários de "Metodologias Ativas" e "Escola Nova", ambos pautados no professor como mediador.

Consideram-se as experiências vivenciadas durante a graduação como meio de incentivar o gosto pela docência, bem como instrumentalizar estratégias enquanto acadêmico sob tutoria de professores capacitados. Inferiu-se sobre o perfil educador do enfermeiro que está em constante evolução e crescimento, pautado no perfil humanista e compromisso com a formação dos futuros profissionais que por meio de competências estruturadas fomenta a qualificação do ensino.

As reflexões ainda trouxeram o "estar desacomodado" como um estado individual e coletivo de abertura para o novo, com a introdução de novos desafios na carreira docente, bem como a introdução de ferramentas atuais como as TIC no contexto da sala de aula. Compreendeu-se a importância da interdisciplinaridade em todo o contexto explanado, com a finalidade de instrumentalizar ferramentas, estratégias e metodologias de ensino e aprendizagem, possibilitando uma avaliação crítica dos resultados alcançados com a intervenção proposta, contribuindo para a formação cidadã crítica e consciente da sua realidade e responsabilidade com o meio.

\section{REFERÊNCIAS}

ANASTASIOU, L. G. C.; PIMENTA, S. G. Docência na Educação Superior. São Paulo: Cortez, 2002.

ANTUNES, C. Como desenvolver as competências em sala de aula. Petrópolis, RJ: Vozes, 2001.

AUDEBERT, C. La Diaspora Haïtienne: Territoires migratoires et réseaux transnationaux. Rennes: Presses Universitaires de Rennes, 2012.

BAKHTIN, M. Os gêneros do discurso. In: BAKHTIN, M. Estética da criação verbal. São Paulo: Martins Fontes, 2003. 
BRASIL. Lei no 7.498 de 25 de junho de 1986. Dispõe sobre a regulamentação do exercício da Enfermagem e dá outras providências. Diário Oficial da República Federativa do Brasil, Brasília, 26 jun.1986. Seção I, p. 8.853 a 8.855.

CARVALHO, I. C. M. Em direção ao mundo da vida: interdisciplinaridade e educação ambiental. IPE 1998.

CAVALCANTI, L.; OLIVEIRA, A. T.; TONHATI, T. (Orgs.) A Inserção dos Imigrantes no Mercado de Trabalho Brasileiro. Cadernos OBMigra, Ed. Especial, Brasília, v. 1, n. 2, 2015 .

DELORS, J. et al.; Relatório para a UNESCO da Comissão Internacional sobre Educação para o século XXI. Educação: um tesouro a descobrir. São Paulo: UNESCO, 1999.

DEMO, P. Universidade, aprendizagem e avaliação: horizontes reconstrutivos. Porto Alegre: Mediação, 2004.

FAUSTINO, R. L. H.; EGRY, E. Y. A formação da enfermeira na perspectiva da educação reflexões e desafios para o futuro. Rev Esc Enferm USP, v. 36, n. 4, p. 332-7, 2002.

FREIRE, P. Pedagogia do oprimido. São Paulo: Paz e Terra, 1996.

GADOTTI, M. Perspectivas atuais da educação. Porto Alegre: Artes Médicas Sul; 2000.

GAUTHIER, C. et al. Por uma teoria da pedagogia: pesquisas contemporâneas sobre o saber docente. 2a ed. Ijuí: Editora Unijuí, 2006.

GHEDIN, E. Tendências e dimensões da formação do professor na contemporaneidade. $4^{\circ} \mathrm{CONPEF}$ - Congresso Norte Paranaense de Educação Física Escolar. Universidade Estadual de Londrina. 2009.

HEIDEGGER, M. A questão da técnica. scientiæ zudia, São Paulo, v. 5, n. 3, p. 375-98, 2007

LIBÂNEO, J. C. Adeus professor, Adeus professora? Novas exigências educacionais e profissão docente. 6 ed. São Paulo: Cortez. 2002.

LIBÂNEO, J. C. Organização da Escola: teoria e prática. Goiânia: Alternativa, 2001.

MASETTO, M. T. (Org.) Docência na universidade. 9. ed. Campinas: Papirus, 2008.

MEJÍA, M. R. G.; CAZAROTTO, R.; GRANADA, D. Migração haitiana no Brasil: análises de um processo em construção a partir de um estudo de caso. Anais-Seminário Internacional sobre Desenvolvimento Regional, 2015.

MELLO, M. C.; RIBEIRO, A. E. A. Competências e habilidades da teoria à prática. Rio de Janeiro: WAK, 2002.

MORAES, I. A.; ANDRADE, C. A. A.; MATTOS, B. R. B. A imigração haitiana para o Brasil: causas e desafios. Revista Conjuntura Austral, v. 4, n. 20, Out./Nov., 2013.

NÓVOA, A. Para uma formação de professores construída dentro da profissão. Revista Education, n. 350, p. 25-34, 2009. 
PASTORIZA, B. S.; PINO, J. C. D. Para Falar de Disciplina, Corpos e Conhecimentos Entre os Muros da Escola. Revista Eletrônica de Educação, v. 9, n. 1, p. 301-317, 2015.

PERRENOUD, P. Construindo competências [entrevista]. Nova Escola, v. 15, n. 135, p. 19-21, 2000.

SCHUCK, R. J. et al. Novas Tecnologias da Informação e Comunicação e ensino: cibercultura e acesso ao conhecimento. Signos, v. 34, n. 2, p. 29-38, 2013.

SCHUCK, R. J.; NEUENFELDT, D. J. O jogo como fio condutor para compreender o compreender. http://www.efdeportes.com/Revista Digital, v. 13, n. 128, jan, 2009

SCHWERTNER, S. F.; CONRAD, J. M. Um click na escola: olhares e discursos de jovens estudantes sobre a instituição escolar contemporânea. Caderno pedagógico, Lajeado, v. 13, n. 2, p. 28-46, 2016.

TARDIF, M.; LESSARD, C. O trabalho docente: elementos para uma teoria da docência como profissão de interações humanas. 6a Ed. Rio de Janeiro: Vozes, 2011.

ZANCANARO, A.; AMIEL, T. The academic production on open educational resources in Portuguese. RIED: Revista Iberoamericana de Educación a Distancia, v. 20, n. 1, p. 81104, 2017. 